\title{
Dry Joint Stone Masonry Walls Subjected to In-Plane Combined Loading
}

\author{
Paulo B. Lourenço'; Daniel V. Oliveira²; Pere Roca ${ }^{3}$; and Agustín Orduña ${ }^{4}$
}

\begin{abstract}
The paper presents the results of experimental research on the structural behavior of dry joint masonry. The most relevant experimental results concern the strength response of stone dry joint masonry walls subjected to in-plane combined compressive and shear loading. Significant features of the structural behavior shown by the walls are discussed and conclusions on their ultimate capacity and observed failure mechanisms are addressed. Complementarily, the application of an existing numerical model, stemming from plasticity and based on a micromodeling strategy, is also presented and discussed with regard to its capacity to simulate the obtained experimental results. The model was calibrated with data collected from complementary tests carried out on specimens and prisms made of the same type of stone. Finally, the usage of a simplified method of analysis based on a continuum of diagonal struts is also addressed.
\end{abstract}

DOI: 10.1061/(ASCE)0733-9445(2005)131:11(1665)

CE Database subject headings: Masonry; Shear walls; Laboratory tests; Structural analysis; Finite elements; Joints; Stiffness; Numerical models.

\section{Introduction}

An important legacy of ancient constructions built with dry joint (or mortarless) masonry exist all over the world, including important monuments such as Greek, Roman, and Medieval constructions in the South of Europe, the temples of the ancient Khmer Empire in Cambodia, or the City of Great Zimbabwe in Africa. Even in not so ancient times, dry joint masonry was preferred in regions where limestone was not readily available. In the Northern part of Portugal, for instance, dry stone masonry constructions are common and lime was a precious material mostly used for rendering. Moreover, a number of historical constructions, originally built with mortar joints, have experienced a significant loss of mortar due to combined chemical, physical, and mechanical degradation. Due to the partial or total disappearance of mortar, the behavior of these constructions becomes similar to those made of dry joint masonry.

The analysis of dry joint masonry constructions, aimed at their

${ }^{1}$ Associate Professor, Dept. of Civil Engineering, Univ. of Minho, Azurém, 4800-058 Guimarães, Portugal. E-mail: pbl@civil.uminho.pt

${ }^{2}$ Assistant Professor, Dept. of Civil Engineering, Univ. of Minho, Azurém, 4800-058 Guimarães, Portugal. E-mail: danvco@ civil.uminho.pt

${ }^{3}$ Full Professor, Dept. of Construction Engineering, Technical Univ. of Catalonia, c/Gran Capitán s/n, mod. C1, 08034 Barcelona, Spain. E-mail: pere.roca.fabregat@upc.edu

${ }^{4}$ Full Professor, Faculty of Civil Engineering, Univ. of Colima, km 9, Colima-Coquimatlán way, 28400, Mexico; formerly, PhD Student, Dept. of Civil Engineering, Univ. of Minho, Azurém, 4800-058 Guimarães, Portugal. E-mail: aord@ucol.mx

Note. Associate Editor: Tso-Chien Pan. Discussion open until April 1, 2006. Separate discussions must be submitted for individual papers. To extend the closing date by one month, a written request must be filed with the ASCE Managing Editor. The manuscript for this paper was submitted for review and possible publication on March 16, 2004; approved on January 31, 2005. This paper is part of the Journal of Structural Engineering, Vol. 131, No. 11, November 1, 2005. CASCE, ISSN 0733-9445/ 2005/11-1665-1673/\$25.00. structural assessment and restoration, demands an adequate understanding of the mechanical behavior of this kind of fabric. However, research on structural masonry has been mostly devoted to the characterization of mortared-joint masonry. As research on dry joint masonry is almost nonexistent, any research in this field opens new possibilities to improve the existing knowledge and to understand its complex behavior. The investigation presented here, oriented to the characterization of the in-plane structural behavior of dry joint elementary walls, contributes to these objectives.

Since the possibility of performing destructive tests on historical constructions, either in situ or by removing samples large enough to be representative, is usually impossible (Macchi 1992), research on masonry is mostly based on laboratory tests. In such tests, careful attention must be paid to the geometric definition and to the adopted materials in order to ensure adequate representation of the existing constructions.

Due to the complexity of the mechanical phenomena involved in their response, the structural analysis of dry joint constructions constitutes a challenge even for the most sophisticated numerical tools. The material discontinuity introduced by the joints makes the use of interface elements, within a finite element formulation, an appropriate option to model such structures (e.g., Lotfi and Shing 1994; Lourenço and Rots 1997; Carol et al. 2001). As the previous work in interface modeling was rooted in masonry made with mortar joints, the set of tests presented here will assist to validate existing numerical models. It is noted that other attractive tools for micromodeling are the discrete element method (Cundall and Hart 1992; Lemos 1997) and limit analysis based on mathematical programming (Gilbert and Melbourne 1994; Baggio and Trovalusci 1996; Orduña and Lourenço 2003). In any case, accurate experimental data concerning elastic and inelastic behavior are required.

The experimental work reported in this paper consisted of a set of seven walls subjected to a vertical precompression level, ranging between 0.15 and $1.25 \mathrm{~N} / \mathrm{mm}^{2}$, which is considered representative of the (low) vertical stresses due to gravity loads usually found in massive ancient structures. After the application of the 


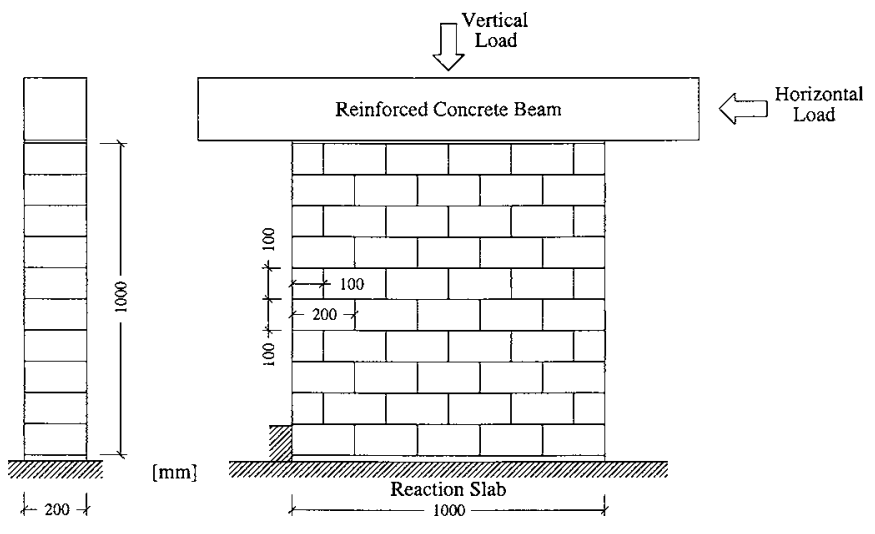

Fig. 1. Adopted geometry for the dry stone masonry walls and schematic loading arrangement

vertical load, a horizontal in-plane load was provided and increased monotonically until reaching the failure of the wall. In brief, the two complimentary objectives of the experimental research program were to contribute to a better knowledge of dry masonry mechanics and to challenge existing sophisticated nonlinear interface modeling tools.

\section{Experimental Research}

The experimental research program was carried out at the Structural Technology Laboratory of the Technical University of Catalonia, Barcelona, in cooperation with University of Minho, concerning the structural behavior of dry joint masonry stone walls. The walls were made of a common and locally available stone (known as "Montjuic stone"), which is present in many monuments spread all over Catalonia. Macroscopically, the stone presents a very homogeneous surface and a very small grain size. Tests carried out on specimens of this stone allowed the measurement of a rather high uniaxial compression strength $\left(82.7 \mathrm{~N} / \mathrm{mm}^{2}\right)$, a Young's modulus of $15,500 \mathrm{~N} / \mathrm{mm}^{2}$ and a specific weight of $25 \mathrm{kN} / \mathrm{m}^{3}$ (Oliveira 2003). The tensile strength of the stone is $3.7 \mathrm{~N} / \mathrm{mm}^{2}$ (Ramos 2002).

In total, seven dry stone masonry shear walls were built and successfully tested subjected to combined vertical and horizontal loading. All the tests were carried out under monotonic loading. Currently, similar tests are being carried out at the University of Minho in order to obtain experimental data about cyclic behavior and to evaluate the safety level of historical constructions in seismic areas.

\section{Wall Construction and Test Procedure}

All the units were mechanically sawn and exhibited smooth surface. The walls were built according to the geometry shown in Fig. 1. It is noted that the first course of the wall is horizontally supported, in order to force nonlinear mechanisms to occur inside a masonry region. The specimens have a square shape, with a side of $1.0 \mathrm{~m}$ and thickness of $0.2 \mathrm{~m}$. Taking into account the available laboratory facilities and equipment, together with the fact that historical structures are usually submitted to low compressive stress states, the vertical load levels adopted for the tests were 30, 100,200 , and $250 \mathrm{kN}$. These load values lead to compressive normal stresses of $0.15,0.50,1.00$, and $1.25 \mathrm{~N} / \mathrm{mm}^{2}$, respectively. The terminology adopted to denote the walls is based on
Table 1. Wall Designation According to the Applied Vertical Load and Number of Specimen

\begin{tabular}{lcc}
\hline Wall designation & $\begin{array}{c}\text { Vertical load } \\
(\mathrm{kN})\end{array}$ & $\begin{array}{c}\text { Normal stress } \\
\left(\mathrm{N} / \mathrm{mm}^{2}\right)\end{array}$ \\
\hline SW.30.1 & 30 & 0.15 \\
SW.30.2 & 30 & 0.15 \\
SW.100.1 & 100 & 0.50 \\
SW.100.2 & 100 & 0.50 \\
SW.200.1 & 200 & 1.00 \\
SW.200.2 & 200 & 1.00 \\
SW.250.1 & 250 & 1.25 \\
\hline
\end{tabular}

the value of the vertical load applied $(x x x)$ and the number of specimen $(y)$, as given in Table 1 by SW.xxx.y.

The construction of the walls was performed manually in different phases. First, a thin layer of self-leveling mortar was laid on the floor in order to correct any potential roughness of the reaction slab. The mortar used was a high strength $\left(\approx 50 \mathrm{~N} / \mathrm{mm}^{2}\right)$ and rapid hardening $(\approx 1$ day) mortar. Then, the stone units were carefully placed in order to preserve verticality and alignment. The stone units with visible defects were rejected. After laying the ten courses of stone units, totaling a height of $1.0 \mathrm{~m}$, a thin layer of self-leveling mortar was laid on the top of the wall. This layer had the aim of linking the last stone course and of enabling a good contact between the top of the wall and the top reinforced concrete beam (dimensions of $0.20 \times 0.20$ $\times 1.60 \mathrm{~m}^{3}$ ). On top of the concrete beam, a wide flange beam steel profile was added (an additional load of $1.0 \mathrm{kN}$ ), where the vertical load was applied. Finally, the wall was instrumented with linear variable differential transformers (LVDTs), in order to measure relative displacements between stone pieces during vertical and horizontal loadings.

The walls were tested one day after their construction, which was possible due to the rapid leveling mortar strength development. The adopted procedure to test the walls was divided in two major steps. Initially, a vertical compressive load was applied by means of a hydraulic actuator, under force control, until the desirable load was totally applied to the wall. Subsequently, the hydraulic actuator was kept under force control, resulting in an applied constant vertical load. Consequently, the beam was allowed to move in vertical and horizontal directions. Afterwards, the horizontal load was applied by imposing small displacement increments. For this purpose, a hydraulic actuator was horizontally fixed and the load was applied against the reinforced concrete beam. During testing, the main events, as opening of the joints and appearance of cracks, were registered by means of photographs (Oliveira 2003).

\section{Response of Walls Subjected to Distributed Vertical Loading}

All walls, with the exception of the series with a $30 \mathrm{kN}$ precompression load (SW.30.1 and SW.30.2), were instrumented with two LVDTs measuring relative vertical displacements of points separated by $0.9 \mathrm{~m}$. The Young's moduli for all the walls, based on these measurements and calculated as the normal average stress divided by the average strain measured, are presented in Table 2. It can be observed that the stiffness of the wall increases with the normal stress. Based on these values, a linear least square regression was assumed to extrapolate the results to the walls 
Table 2. Young's Modulus of the Walls: Vertical Load Test Results and Linear Least Square Regression

\begin{tabular}{lrrr}
\hline & \multicolumn{3}{c}{ Young's modulus $\left(\mathrm{N} / \mathrm{mm}^{2}\right)$} \\
\cline { 2 - 4 } Wall & $E_{\text {test1 }}$ & $E_{\text {test2 }}$ & $E_{\text {calc }}$ \\
\hline SW.30 & - & - & 566 \\
SW.100 & 824 & 688 & 768 \\
SW.200 & 969 & 1,302 & 1,057 \\
SW.250 & 1,024 & 1,353 & 1,202 \\
\hline
\end{tabular}

SW.30 and to validate the approach. The Young's moduli calculated from the linear regression are given both in Table 2 and Fig. 2. It is observed that:

- The values calculated by the linear regression are in the range of only $3.5-7.5 \%$ of the Young's modulus of the separately tested stone and

- Young's modulus of the walls increases with the vertical load, meaning that dry stone masonry assemblages exhibit a peculiar elastic non-linear behavior, with increasing stiffness upon compressive loading.

The extremely low stiffness value of the stone walls and the unusual dependency of the stiffness on the compressive loading is explained by geometric tolerances and the absence of a leveling mortar. In fact, the stone units are partly in contact with each other, creating an imperfect joint with localized contacts. The increasing contact between stone units (or the closing of the joints) under higher normal stresses justifies the stiffness increase. The joint closure feature is a well-known phenomenon in rock mechanics (Bandis et al. 1981; Sun et al. 1985). Moreover, rock joints exhibit hysteric behavior with partial joint closure upon cyclic loading.

\section{Load-Displacement Diagrams and Observed Damage for Combined Vertical and Horizontal Loading}

From the amount of experimental data collected during the tests, ranging from applied loads to relative displacements between stone units, one of the most significant aspects is the relation between the horizontal load and the horizontal displacement, which is shown in Fig. 3. The walls tested with the same compressive load are presented in the same diagram, for a better comparison. The horizontal displacement was computed as the differ-

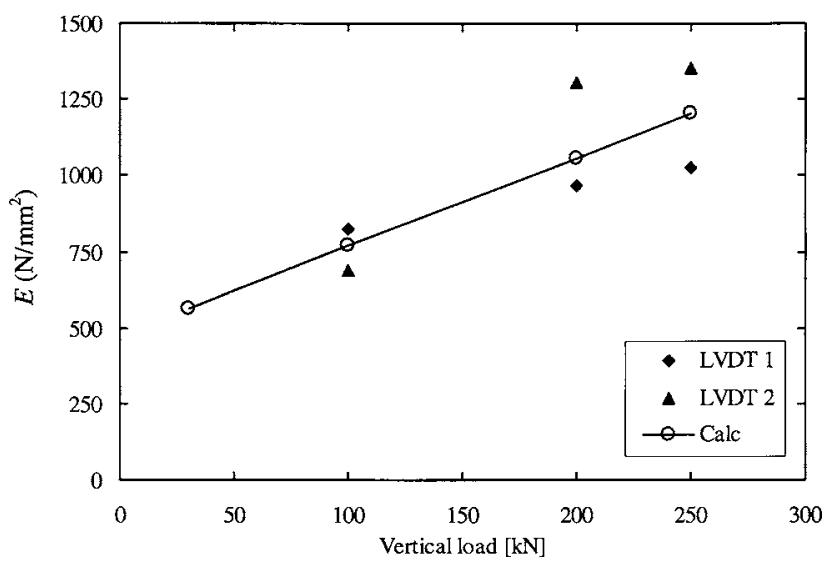

Fig. 2. Young's modulus versus applied vertical load
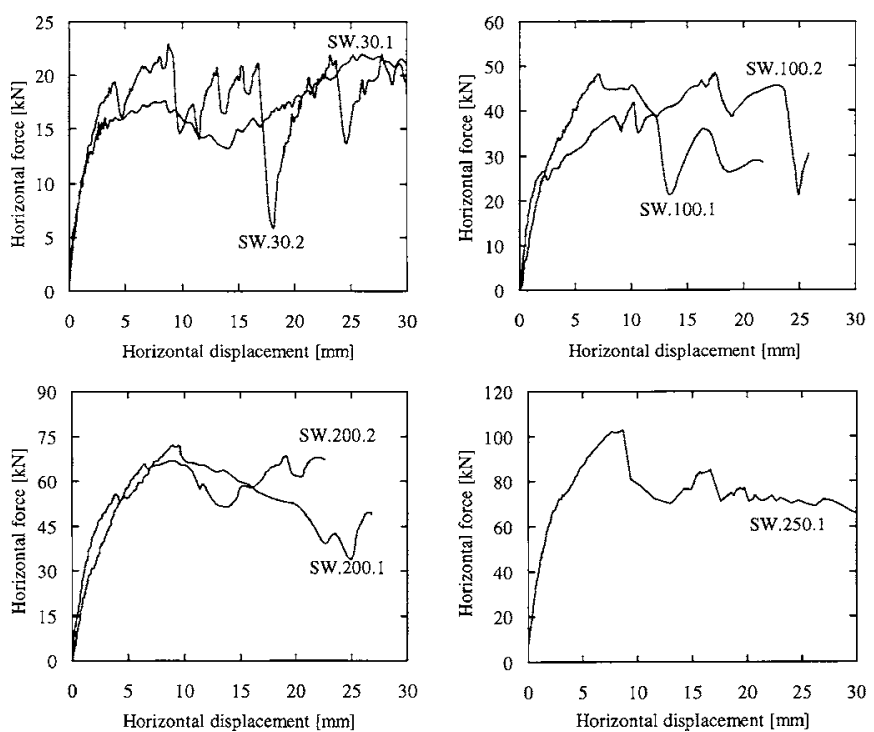

Fig. 3. Horizontal load-displacement diagrams of the seven tested walls, sorted by equal applied vertical load

ence between the horizontal displacement of the beam and the displacement measured at the bottom of the wall (which was confirmed to be negligibly small).

The horizontal load-displacement diagrams are characterized by two main distinct behaviors. Initially, the curves exhibited large stiffness with linear behavior up to $30 \%$ of the respective peak load. Then, continuous stiffness degradation takes place under increasing horizontal displacement. The second part of the diagrams is characterized by an oscillation of the horizontal load in all diagrams, showing a series of consecutive increments and sudden decrements as the lateral deformation increases. Such oscillation was caused by sudden relative stone movements and can be attributed to the fact that no interlayer material existed. Nevertheless, relatively ductile responses could be obtained, indicating that collapse is mostly controlled by shear failure and rocking, with moderate crushing at the compressed toe. This observation is further confirmed by the very significant drift measured in the experiments (always larger than 2.5\%) and by the fact that the compressive strength of the stone is rather high.

The failure pattern of each wall is shown in Figs. 4 and 5. The pictures show that the failure mode is linked to the level of applied vertical load. This result is already well known for regular masonry (e.g., Page et al. 1980; Mann and Müller 1982).

For lower stress levels, failure occurred by simple rotation of the upper part of the wall and sliding along the bed joints, leading to a stepped diagonal crack without visible cracking in the stone units, see Fig. 4. For higher vertical loads, the tendency of the walls to experience this rigid body movement gradually vanished. Cracking in the stone units started to become noticeable, being the stepped diagonal crack partially replaced by a diagonal cracking band developed along the joints and through stone units, which showed visible damage, see Fig. 5. Also, horizontal displacements along the diagonal band were clearly noticeable. As expected, more intense damage in stone units was observed in the walls initially subjected to a higher vertical load.

The experiments suggest that, even for moderate vertical loads, failure of dry masonry walls subject to combined in-plane vertical and horizontal loads will normally involve diagonal 


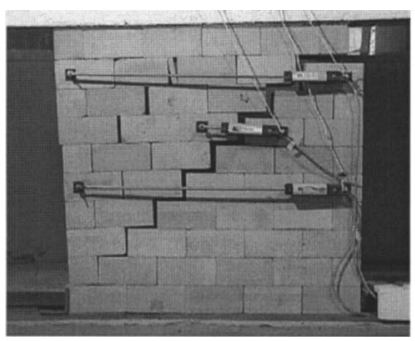

SW.30.1

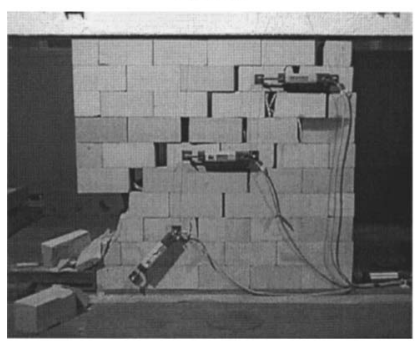

SW.100.1

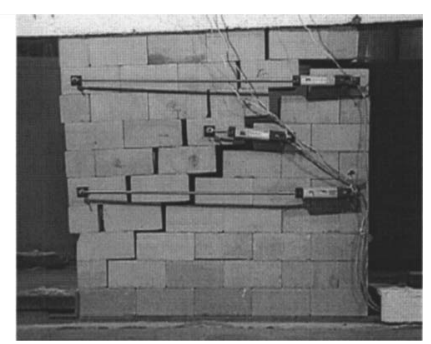

SW.30.2

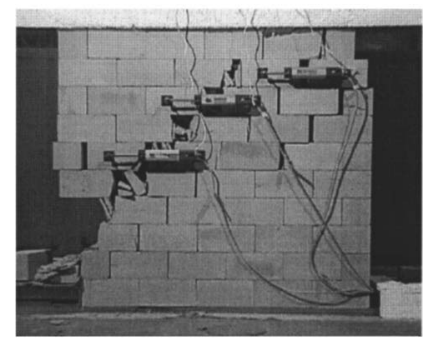

SW. 100.2
Fig. 4. Failure modes observed (vertical load equal to 30 and $100 \mathrm{kN}$ )

cracking across the units rather than the sole sliding of the bed joints. Naturally, this phenomenon may be highly dependent on the tensile strength of the stone units.

The lack of an interlayer material induced stress concentrations in the contact points, leading to premature vertical cracking of the stone units. It must be stressed that cracking of stone units occurred even for walls with an initial vertical stress applied of only $0.5 \mathrm{~N} / \mathrm{mm}^{2}$. Naturally, this cracking process was much more relevant for higher vertical loads.

It is also noted that for moderate vertical stresses $\left(1.25 \mathrm{~N} / \mathrm{mm}^{2}\right)$, the risk of premature failure by lateral buckling becomes important. One of the two specimens initially loaded to $250 \mathrm{kN}$ (corresponding to $1.25 \mathrm{~N} / \mathrm{mm}^{2}$ ) failed prematurely, with only a small amount of horizontal load applied, because of this

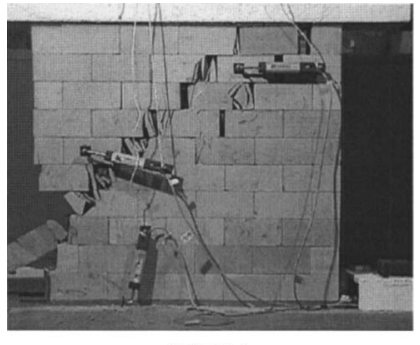

SW. 200.1

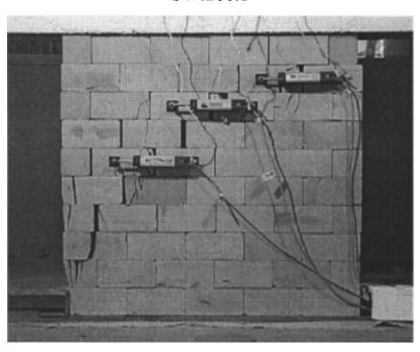

SW. 250.1

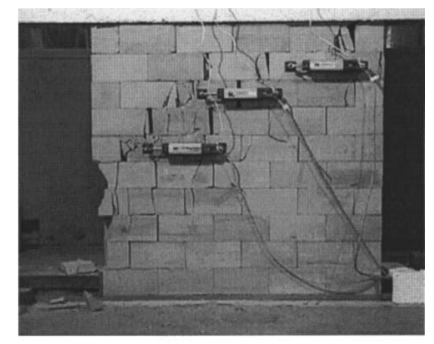

Sw. 200.2

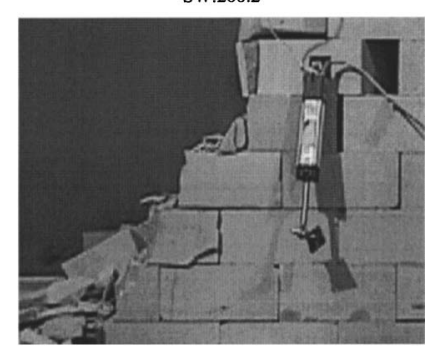

SW.250.1
Fig. 5. Failure modes observed (vertical load equal to 200 and $250 \mathrm{kN})$
Table 3. Vertical and Maximum Horizontal Loads Measured

\begin{tabular}{lcc}
\hline & $\begin{array}{c}\text { Vertical } \\
\text { load } \\
(\mathrm{kN})\end{array}$ & $\begin{array}{c}\text { Maximum horizontal } \\
\text { load } \\
(\mathrm{kN})\end{array}$ \\
\hline SW.30.1 & 30 & 22 \\
SW.30.2 & 30 & 23 \\
SW.100.1 & 100 & 42 \\
SW.100.2 & 100 & 49 \\
SW.200.1 & 200 & 72 \\
SW.200.2 & 200 & 69 \\
SW.250.1 & 250 & 102 \\
\hline
\end{tabular}

phenomenon. This is due to the fact that dry masonry may not keep aligned during testing since small geometric irregularities may cause the stone units to move out-of-plane.

\section{Failure Envelope (Relation between Average Normal and Shear Stresses)}

Usually, test results concerning in-plane testing of walls subjected to compressive and shear loading are presented in terms of a relationship between average normal and shear stresses at failure, where the average represents the measured ultimate loads divided by the full cross section of the wall. This procedure does not account either for local peak stresses that certainly influence failure or for the change in the contact, or effective, cross section. Still, it was decided to investigate such a possible relation, which is of interest from an engineering perspective.

Table 3 summarizes the values obtained for the vertical and maximum horizontal loads, for all tests. It can be observed that the maximum horizontal load increases with the vertical load applied, as expected. A graphic representation, in terms of stresses, is shown in Fig. 6, which also presents two least square regressions. The normal $(\sigma)$ and tangential $(\tau)$ stresses were obtained by dividing the vertical and horizontal forces by the wall crosssectional area (bed joint area). Again, these stresses represent average values since neither vertical nor horizontal stresses are constant along the bed joint.

The linear least square regression computed for the seven walls showed a good approximation to the experimental data,

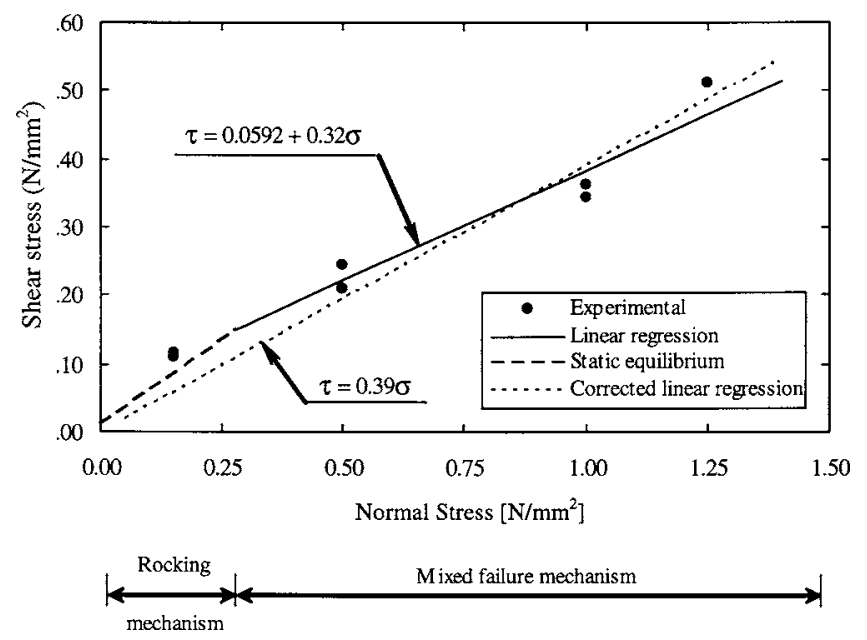

Fig. 6. Relation between normal and tangential stresses: Experimental data and linear least square regressions 


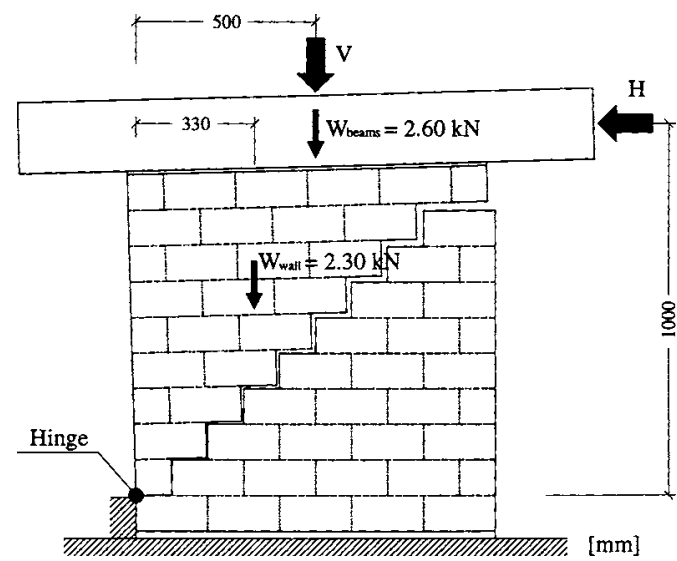

Fig. 7. Rocking failure mechanism for low externally applied vertical load $V$

with a correlation coefficient $r^{2}=0.98$. The resulting relationship between shear and normal average stresses is $\tau=0.0592+0.32 \sigma$. However, this approximation implies an artificially high cohesion value $\left(0.059 \mathrm{~N} / \mathrm{mm}^{2}\right)$, given by the tangential strength value for zero normal stress. Two possibilities exist to correct this, in principle, unacceptable solution.

The first possibility consists of a linear least square regression with zero cohesion: $\tau=0.39 \sigma$. In this case, a slightly lower correlation coefficient is obtained $\left(r^{2}=0.95\right)$, but the first two points (SW.30.1 and SW.30.2) are weakly approximated. The horizontal load value $H$ is equal to $11.7 \mathrm{kN}$, which is clearly too low $(52 \%$ of the measured experimental value).

The second possibility consists of a bilinear envelope. Such an envelope is in agreement with the well known failure criterion of Mann and Müller (1982) although the meaning of the failure modes corresponding to the two branches is slightly different. The first branch corresponds to a rocking mechanism and the second corresponds to a mixture of sliding, cracking in the stone units and crushing of the compressed toes, see Fig. 6 (in Mann and Müller's criterion (1982), intended for mortared-joint masonry, the first branch corresponds to sliding and the second to cracking of units). This preliminary hypothesis must be adopted with caution because more work is needed regarding block size, surface roughness, irregular bond patterns, etc.

As the failure mechanism for low vertical stresses is pure rocking, the correct value of the horizontal force $H$ can be easily calculated from statics, see Fig. 7, as

$$
H=\left(W_{\text {beams }}+V\right) \times 0.50+W_{\text {wall }} \times 0.33=2.06+0.50 V
$$

If Eq. (1) is recast in terms of stresses, the following expression is found: $\tau=0.0103+0.50 \sigma$, meaning that the first two points (SW.30.1 and SW.30.2) are better approximated. In this case, the horizontal load value $H$ is equal to $17.1 \mathrm{kN}$ ( $76 \%$ of the measured experimental value).

Finally, it is stressed that the obtained friction coefficient of the walls for the different cases (0.32 and 0.39) is much lower than the tangent of the friction angle of the stone joints, $\tan \phi$, which was experimentally found to be equal to 0.62 (Lourenço and Ramos 2004). A well know fact is that the joint values and the wall values have different physical meanings.

\section{Numerical Modeling}

Complementary to the experimental research described, a numerical simulation of the tested stone walls was carried out, to further discuss and better understand the experimental results. The numerical analyses were performed using the multisurface interface model proposed by Lourenço and Rots (1997). This model is fully based on plasticity theory and assumes that stone units behave in an elastic fashion whereas inelastic behavior is concentrated in the joints (the so-called micromodeling strategy).

In the numerical simulations, the stone units were modeled using eight-node continuum plane stress elements with Gauss integration and, for the joints, six-node zero-thickness line interface elements with Lobatto integration were used. The boundary conditions and the load application procedure were defined according to the experimental arrangement described before.

\section{Elastic Parameters}

The usage of a micro-modeling approach based on interface finite elements requires two distinct stiffnesses, namely, the stiffness of the stone units, given previously, and the stiffness of the joints.

Once the stiffness of the stone units is fixed, the stiffness of the joints can be obtained from the experimental data of vertical displacements measured during the vertical load application. For that purpose, the values previously given in Table 2 are considered. The variation of the stiffness of the wall with the applied vertical load is associated with the complex behavior of dry joint masonry structures and leads to increasing difficulties in adequately modeling its structural behavior. Thus, modeling dry masonry structures seems to require the coupling of nonlinear elastic behavior with a history control for loading cycles, aiming at reproducing stiffness increase as a function of the compressive load. Given the lack of experimental data available for dry stone masonry joints, this feature is indirectly considered here by adopting the experimentally measured joint stiffness in each wall model, as a function of the vertical load applied to the wall.

The normal joint stiffness $k_{n \text {,joint }}$ can be easily calculated by considering the wall as a series of two vertical springs, one representing the stone unit and the other representing the joint. This assumption leads to

$$
k_{n, \text { joint }}=\frac{1}{h\left(\frac{1}{E_{\text {wall }}}-\frac{1}{E_{\text {stone }}}\right)}
$$

where $h=$ height of the stone unit (equal to $100 \mathrm{~mm}$ ); $E_{\text {wall }}=$ Young's modulus of the wall (given in Table 2); and $E_{\text {stone }}=$ Young's modulus of the stone (assumed equal to $15,500 \mathrm{~N} / \mathrm{mm}^{2}$ ). In the absence of more information, the tangential stiffness $k_{s \text {,joint }}$ can be calculated directly from the normal stiffness, assuming that the theory of elasticity is directly applicable, as

$$
k_{s, \text { joint }}=\frac{k_{n, \text { joint }}}{2(1+\nu)}
$$

where $v=$ Poisson's ratio (assumed equal to 0.2 ). Table 4 provides the stiffness of the joints calculated with these assumptions, later validated by the numerical results. 
Table 4. Stiffness Calculated for the Joints

\begin{tabular}{lcc}
\hline Walls & $\begin{array}{c}k_{n} \\
\left(\mathrm{~N} / \mathrm{mm}^{3}\right)\end{array}$ & $\begin{array}{c}k_{s} \\
\left(\mathrm{~N} / \mathrm{mm}^{3}\right)\end{array}$ \\
\hline SW.30 & 5.87 & 2.45 \\
SW.100 & 8.08 & 3.37 \\
SW.200 & 11.4 & 4.73 \\
SW.250 & 13.0 & 5.43 \\
\hline
\end{tabular}

\section{Inelastic Parameters}

In the case of dry stone masonry joints, the tensile strength and cohesion are equal to zero. Obviously, this renders the numerical analysis more demanding because almost all the joints will behave in a nonlinear fashion. Next, the complete parameters required by the adopted constitutive model (Lourenço and Rots 1997) are reviewed for the sake of clarity. The tensile behavior of the sandstone has been characterized by Ramos (2002), where a tensile strength of $3.7 \mathrm{~N} / \mathrm{mm}^{2}$ and a fracture energy of $0.11 \mathrm{~N} \mathrm{~mm} / \mathrm{mm}^{2}$ were found. For the shear behavior of the stone joints, a value of 0.62 was found for tan $\phi$ and a value of zero was found for $\tan \psi$ (Lourenço and Ramos 2004), being $\phi$ and $\psi$ the friction and dilatancy angles of the stone joints, respectively. The uniaxial compressive strength of the block assembly is $57 \mathrm{~N} / \mathrm{mm}^{2}$ from tests in masonry wallets (Oliveira 2003). As no experimental data are available, the fracture energy in compression was assumed to be half of the value given by Model Code 90 (CEB-FIB 1990) for concrete, due to the higher brittleness of stone.

\section{Calculated Results}

From the experimental results described previously, the walls with a vertical load of 30 and $100 \mathrm{kN}$ exhibited limited stone cracking. For this reason, the possibility of cracking through the stone units was not considered in the finite element model. On the contrary, potential cracks through the middle of the units were considered for the walls with a vertical load of 200 and $250 \mathrm{kN}$. Fig. 8 illustrates the load-displacement diagrams from all the tests, as well as the numerical results, up to a displacement of $15 \mathrm{~mm}$, when the failure mechanism is fully formed. Table 5
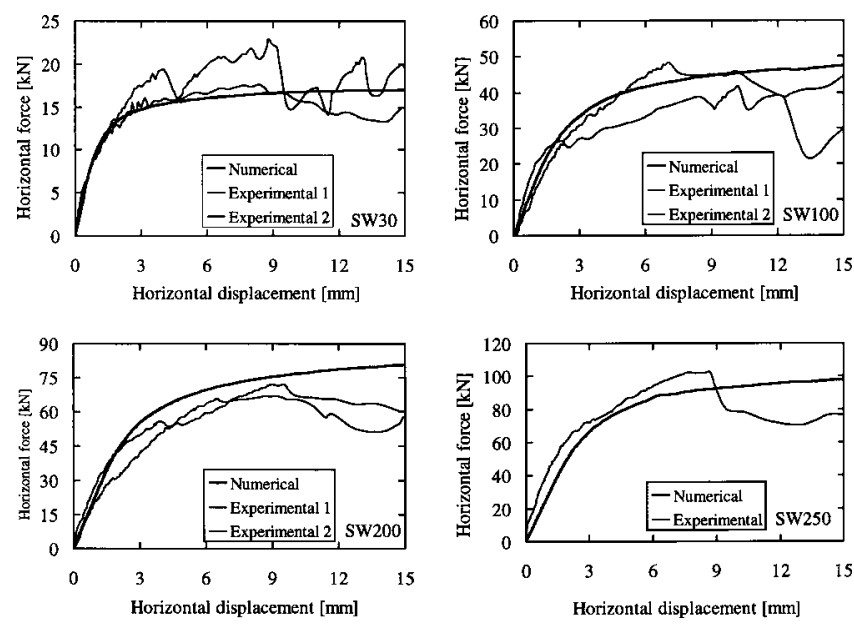

Fig. 8. Horizontal load-displacement diagrams for all walls (the thicker line indicates the numerical result)
Table 5. Comparison of Experimental and Numerical Collapse Loads

\begin{tabular}{lccc}
\hline Walls & $\begin{array}{c}\text { Experimental } \\
(\mathrm{kN})\end{array}$ & $\begin{array}{c}\text { Numerical } \\
(\mathrm{kN})\end{array}$ & Ratio $\frac{\text { numerical }}{\text { experimental }}$ \\
\hline SW.30 & 22.4 & 17.0 & 0.76 \\
SW.100 & 45.0 & 47.5 & 1.06 \\
SW.200 & 70.3 & 81.4 & 1.16 \\
SW.250 & 102.7 & 98.0 & 0.95 \\
\hline
\end{tabular}

Note: The experimental value represents the average of two tests (except for SW.250).

presents the differences between the numerical and experimental collapse loads, where the experimental collapse load represent the average of two tests, when applicable.

The agreement between experimental and numerical responses is rather satisfactory, which a maximum error of $24 \%$ for walls SW.30 and an average error for the four walls of $13 \%$. It is also stressed that the numerical result obtained for walls SW.30 is equal to the simplified hand calculation based on the rocking mechanism of Fig. 7 and provided in the "Experimental Research" section.

Together with the global load-displacement response, a comparison in terms of the deformed mesh and the failure pattern is necessary to appraise the validity of the numerical analyses. Figs. 9 and 10 show a representation of the minimum (compressive) principal stresses for the SW.30 and SW.200 models, on the incremental deformed mesh. The incremental deformed mesh represents the deformation during the last load step, which is different from the total deformed mesh except in the ultimate loading stage. It allows a severely magnified picture of the deformation mechanism active in each load step.

For lower vertical loads, see Fig. 9, it is possible to observe separation of the stone units through diagonal cracks that gradually progress from the bottom courses to the top, while the number of active compressive struts decreases. The stone units "fall" subjected to their own weight, which represent a significant challenge for the robustness of numerical procedures due to bifurcations (multiple solutions). Finally, an overturning (or rocking) failure mechanism is found with a complete diagonal crack through head and bed joints. This failure pattern agrees rather well with the experimental failure mechanisms, see Fig. 4 (SW.30). It is noted that, at this stage, the compressive stresses are still rather low, with respect to the peak compressive stress of the dry stone assemblage.

For higher vertical loads, see Fig. 10, the onset of diagonal cracking is delayed to great extent. Up to a horizontal displacement of $1 \mathrm{~mm}$, no diagonal compressive struts are clearly formed and the complete wall is still structurally active. When diagonal cracking starts to occur, it seems that some shear is always transmitted to the lower part of the wall. A complete diagonal crack fails to propagate and the failure mode seems to be mostly controlled by shear, together with localized rocking of the cracked stone pieces in the compressed toe of the wall. This agrees reasonably well with the failure mechanisms observed in Fig. 4 (SW.100) and Fig. 5. Again, the compressive stresses are low in comparison with the peak compressive stress of the block assemblage. The numerical results indicate that the "crushing" observed in the experiments is in fact a combination of shear and tensile failure of the stone. As the grain of the stone is rather fine, very low dissipation of energy occurs during cracking. In the numerical analysis, in order to obtain adequate agreement with the experiments, as shown in Fig. 8, a full crack was propagated 


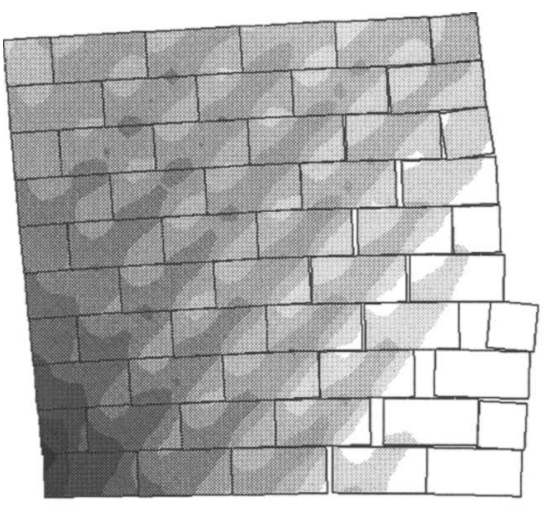

(a)

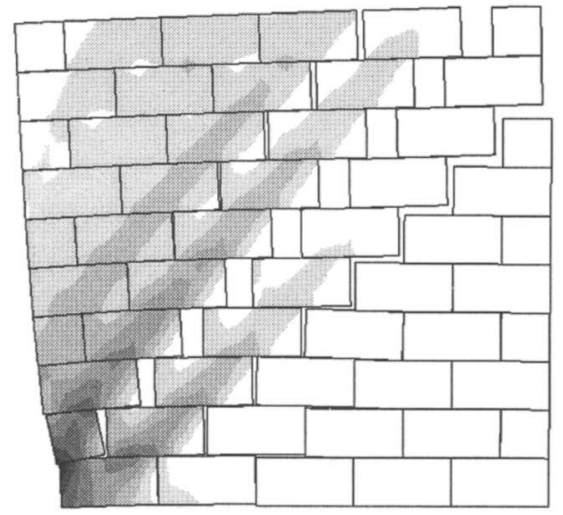

(c)
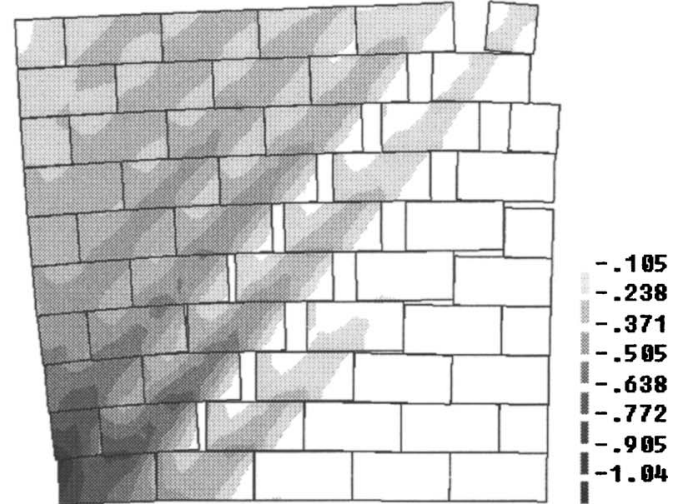

(b)

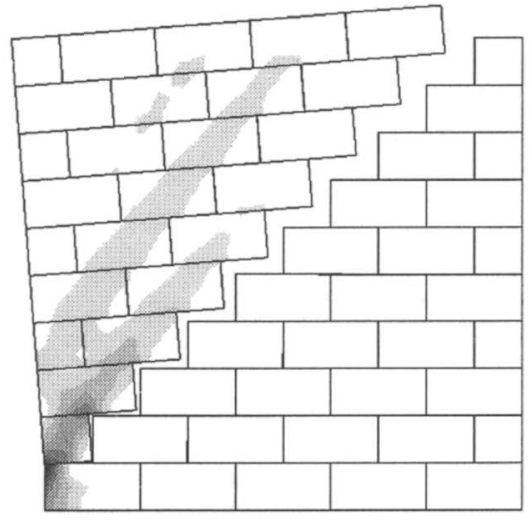

(d)

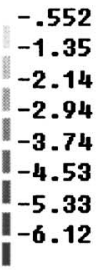

Fig. 9. SW.30. Principal compressive stresses $\left(\mathrm{N} / \mathrm{mm}^{2}\right)$ depicted on the incremental deformed mesh for a horizontal displacement equal to (mm): (a) 1.0 ; (b) 2.0 ; (c) 3.0 ; and (d) 15.0

through the middle of the units once the peak tensile strength of the stone was reached (i.e., brittle behavior was assumed). The use of the fracture energy measured by Ramos (2002) for the potential cracks in the middle of the units, resulted in overly high collapse load values. This, again, allows the conclusion that the stress concentration at the localized irregular contacts between the stone units conducts to instantaneous crack propagation in the stone units.

The numerical results indicate that significant higher collapse loads would be found for walls SW.200 and SW.250 if bedding of the stone units even with a very weak bonding agent, was present. Therefore, it seems not advisable to use dry stone masonry in combination with moderate vertical loading, in areas of strong seismic activity.

\section{Simplified Analysis Methods}

The possibility of estimating the ultimate capacity of the walls by means of a simplified calculation is also considered. For that purpose, a simple mechanism, consisting of a continuum of diagonal struts distributed partly as a fan and partly in parallel, is adopted to represent the ultimate condition of dry joint walls subjected to in-plane loading, see Fig. 11(a). In this mechanism, the maximum slope of the struts with respect to the vertical is limited by the angle of friction of the joint-stone interface, while the maximum vertical compression produced at the base of the fan [dimension $m$ in Fig. 11(a)] is limited to the compressive strength of the fabric. Note that uniform vertical load requires the horizontal load to be distributed according to a specific, nonuniform, scheme.

The equilibrium condition leads to the following expression for the estimation of the maximum horizontal force:

$$
H=V \tan \phi\left[1-\frac{h}{2 b} \tan \phi\left(\frac{1}{1-v}\right)\right]
$$

where

$$
v=\frac{m}{b}=\frac{V}{t b f_{c}}
$$

and $H=$ maximum horizontal force; $V=$ applied total vertical force; $b, h, t=$ length, height, and thickness of the wall, respectively; and $f_{c}=$ average compressive strength of the fabric.

Applying Eq. (4) to the experimental walls leads to an almost linear relationship between the maximum horizontal force and applied vertical force, see Fig. 11(b). The tangent of the obtained linear diagram, equal to 0.42 , is in acceptable agreement with the value of 0.39 resulting from the corrected linear regression corresponding to the experiments, cf. Fig. 6.

The error in the estimation of the maximum horizontal load of walls W100.1, W100.2, and W250 is $10 \%$ or less. However, the simple model overestimates the ultimate horizontal force of walls SW200.1 and SW200.2 in which, as already discussed in the previous section, the failure is very much influenced by early cracking of the units.

In spite of the simplicity of the approach, the model allows a certain understanding of the load bearing capacity nature of the walls, while providing a straightforward explanation for the rela- 


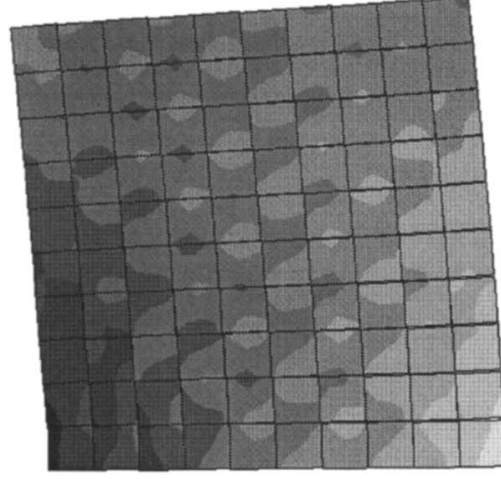

(a)

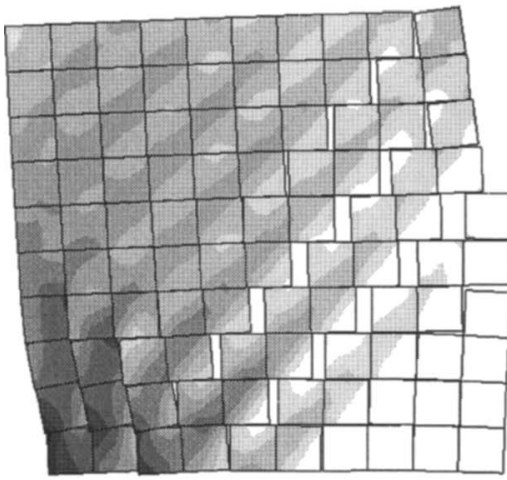

(c)

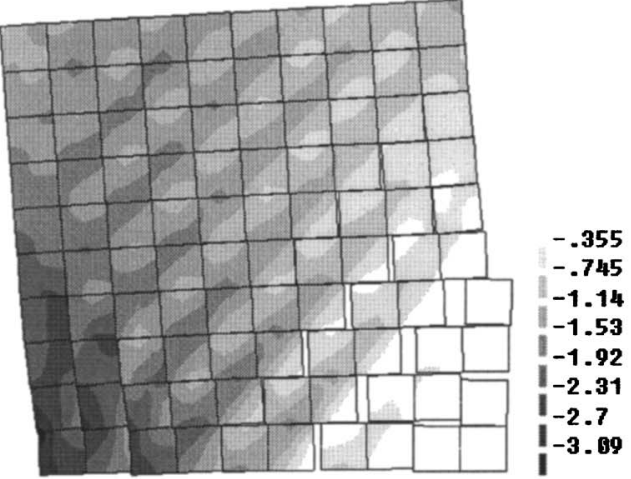

(b)

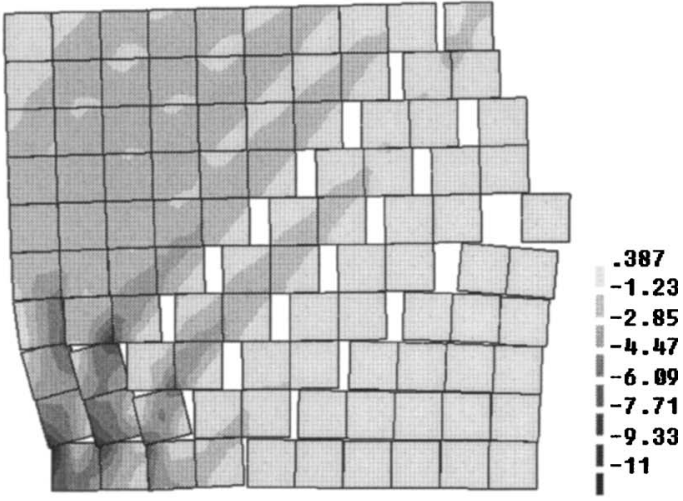

(d)

Fig. 10. SW.200. Principal compressive stresses $\left(\mathrm{N} / \mathrm{mm}^{2}\right)$ depicted on the incremental deformed mesh for a horizontal displacement equal to (mm): (a) 1.0; (b) 3.0; (c) 4.0; and (d) 15.0

tionship between the frictional response of the joints (characterized by $\tan \phi)$ and the "macroscopically" resulting relationship between maximum vertical and horizontal forces acting on the wall.

Certainly, significant phenomena observed in plain stone or brick masonry, such as anisotropy, dilatancy, or the acknowledged influence of the size and geometry of the units, cannot be easily included in a simple description of ultimate equilibrium as the one presented. Nevertheless, the present study suggests that simple models might be useful to derive first-approach calculation methods or even engineering criteria for the characterization of the ultimate response of shear walls. In any case, the calibration and validation of useful simple models requires additional evi-

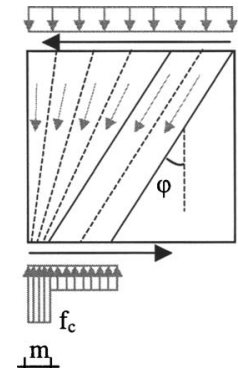

(a)

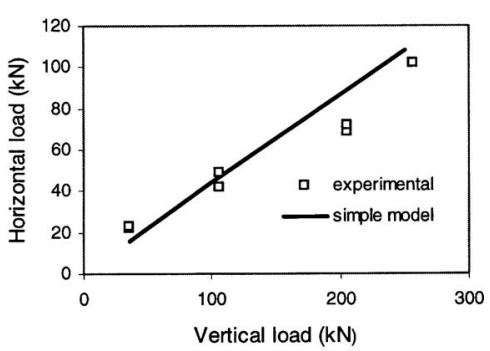

(b)
Fig. 11. Simplified model of analysis: (a) Proposed model describing equilibrium at ultimate condition; and (b) resulting maximum horizontal load compared with the experimental results dence stemming from experiments and numerical simulation based on detailed numerical methods such as the multisurface interface model here described.

\section{Conclusions}

Experimental results on dry joint stone masonry walls, allowing novel insight on aspects of the mechanical response of this type of masonry, have been presented and discussed.

The horizontal load-displacement diagrams, obtained for walls subjected to combined vertical and horizontal loading, are characterized by two main features. Initially, the diagrams showed large stiffness with linear behavior preserved up to almost $30 \%$ of the peak load. Then, continuous stiffness degradation took place under increasing deformation followed by severe oscillations of the horizontal load due to sudden movement of the stone units. The resulting failure modes are clearly associated with the amount of vertical load initially applied. In the walls subjected to lower vertical load, failure occurred by rotation and sliding of part of the wall, whereas for higher vertical loads cracking of the stone units started to become noticeable.

Remarkably, the walls exhibit a significant increase of stiffness with the amount of vertical compression provided to them.

The numerical modeling enabled a detailed simulation of the response of the walls throughout the load process leading to failure. The prediction of the collapse loads and the evolution of the deformed meshes were both in accordance with the experiments. The analysis had provided significant insight into the mechanical response of the walls, showing, in particular, that rapid crack 
propagation occurs under high compressive stresses.

A simplified method of analysis, based on the consideration of a simple ultimate mechanism, was also assessed. In spite of its simplicity, this approach allowed a certain understanding of the ultimate condition of the walls while also providing a prediction for the ultimate loads. However, the possibility of applying simple calculation methods is still requiring more refined models adequately calibrated with additional experimental research.

\section{References}

Baggio, C., and Trovalusci, P. (1998). "Limit analysis for no-tension and frictional three-dimensional discrete systems." Mech. Struct. Mach., 26(3), 287-304.

Bandis, S., Lumsden, A. C., and Barton, N. R. (1981). "Experimental studies of scale effects on the shear behaviour of rock joints." Int. J. Rock Mech. Min. Sci., 18(1), 1-21.

Carol, I., López, C., and Roa, O. (2001). "Micromechanical analysis of quasi-brittle materials using fracture-based interface elements." Int. J. Numer. Methods Eng., 52(1-2), 193-215.

Comité Euro-International du Béton (CEB-FIP). (1990). "CEB-FIP Model Code 1990." Bulletin d'information 195/196, Lausanne, Switzerland.

Cundall, P. A., and Hart, R. D. (1992). "Numerical modeling of discontinua." Eng. Comput., 9, 101-113.

Gilbert, M., and Melbourne, C. (1994). "Rigid-block analysis of masonry structures." Struct. Eng. 72(21), 356-361.

Lemos, J. V. (1997). "Discrete element modeling of the seismic behavior of stone masonry arches." Computer methods in structural masonry, G. N. Pande, J. Middleton, and B. Kralj, eds., E \& FN Spon, London, 4, 220-227.

Lotfi, H., and Shing, P. B. (1994). "Interface model applied to fracture of masonry structures." J. Struct. Eng., 120(1), 63-80.

Lourenço, P. B., and Ramos, L. F. (2004). "Characterization of cyclic behavior of dry masonry joints.” J. Struct. Eng., 130(5), 779-786.

Lourenço, P. B., and Rots, J. G. (1997). "Multisurface interface model for the analysis of masonry structures." J. Eng. Mech., 123(7), 660-668.

Macchi, G. (1992). "Structural diagnosis and rehabilitation of historical buildings." Cuadernos Intemac, 7.

Mann, W., and Müller, H. (1982). "Failure of shear-stressed masonry-an enlarged theory, tests and application to shear walls." Proc. Br. Ceram. Soc., 30, 223-235.

Oliveira, D. V. (2003). "Experimental and numerical analysis of blocky masonry structures under cyclic loading." $\mathrm{PhD}$ dissertation, Univ. of Minho, Guimarães, Portugal, available from 〈www.civil.uminho.pt/ masonry .

Orduña, A., and Lourenço, P. B. (2003). "Cap model for limit analysis and strengthening of masonry structures." J. Struct. Eng., 129(10), 1367-1375.

Page, A. W., Samarasinghe, W., and Hendry, A. W. (1980). "The failure of masonry shear walls." Int. J. Masonry Constr., 1(2), 52-57.

Ramos, L. F. (2002). "Experimental and numerical analysis of historical masonry structures" MSc thesis, Univ. of Minho, Guimarães, Portugal, available from 〈www.civil.uminho.pt/masonry (in Portuguese).

Sun, Z., Gerrard, C., and Stephensson, O. (1985). "Rock joint compliance tests for compression and shear loads." Int. J. Rock Mech. Min. Sci., 22(4), 197-213. 